\title{
Inflammatory myofibroblastic tumours of the maxillary sinus: A brief clinical report and review of the literature
}

\author{
AS Murthy $\mathrm{MD}^{1}$, S Albert MD², C Klonk MD ${ }^{3}$
}

AS Murthy, S Albert, C Klonk. Inflammatory myofibroblastic tumours of the maxillary sinus: A brief clinical report and review of the literature. Plast Surg 2014;22(3):211-212.

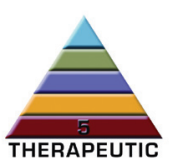

Although inflammatory myofibroblastic tumours (IMTs) have been accepted as a clonal neoplasm, their pathology is poorly understood due to variable presentation. There is no identifiable cause and they are usually observed as tumour growth combined with inflammation. In the current WHO classification, IMTs are designated as intermediate malignancies. In terms of biological potential, IMTs are classified under 'rarely metastasizing'. IMTs are rare in the maxillary sinus but, when reported, can be locally aggressive or even destructive if they invade the orbit. The authors present a brief clinical report describing a five-year-old girl with a slow-growing mass in the right maxillary sinus extending into the lacrimal sac and its management.

Key Words: IMT; Inflammatory tumour; Maxillary sinus tumour; Myofibroblastic tumour
Les tumeurs myofibroblastiques inflammatoires du sinus maxillaire : un bref rapport clinique et une analyse bibliographique

Même si les tumeurs myofibroblastiques inflammatoires (TMI) font partie des néoplasmes clonaux, on comprend mal leur pathologie en raison de leurs présentations variables. De cause non identifiable, elles prennent généralement la forme de croissances tumorales combinées à une inflammation. Selon la classification actuelle de l'OMS, les TMI font partie des tumeurs intermédiaires. Pour ce qui est de leur potentiel biologique, elles se " métastasent rarement ». Les TMI sont rares dans le sinus maxillaire, mais lorsqu'elles se produisent, elles peuvent être agressives localement ou même destructives si elles envahissent l'orbite. Les auteurs présentent le bref rapport clinique et la prise en charge d'une fillette de cinq ans ayant une masse du sinus maxillaire droit à croissance lente qui s'étend dans le sac lacrymal.

A lthough inflammatory myofibroblastic tumours (IMTs) are A accepted as a clonal neoplasm, their pathology is poorly understood due to variable presentation. There is no identifiable cause and they are usually observed as tumour growth mixed with inflammation. In the current WHO classification, IMTs are designated as intermediate malignancies and, in terms of biological potential, they are classified as 'rarely metastasizing' (1). IMTs are rare in the maxillary sinus but, when reported, can be locally aggressive or even destructive if they invade the orbit (2). We present a brief clinical report describing a five-year-old girl with a slow-growing mass in the right maxillary sinus extending into the lacrimal sac and its management.

\section{CASE PRESENTATION}

A five-year-old girl presented with epiphora of the right eye. She had papilledema and a palpable bump on the medial orbital rim. Computed tomography imaging confirmed a mass in the maxillary sinus extending into the lacrimal sac (Figure 1). A biopsy was performed to obtain tissue for diagnosis. Pathological review was suggestive of IMT. Immunohistochemical studies revealed uniform expression of smooth muscle actin in a characteristic 'tram track' pattern supportive of myofibroblastic differentiation (Figure 2). The tumour was negative for anaplastic lymphoma kinase (ALK) protein expression, S-100 protein, wide-spectrum cytokeratin and desmin. Based on these findings, surgical intervention was recommended. She underwent a medial maxillectomy with frozen-section control and dacrocystorhinostomy. She experienced an uneventful postoperative course. She did have papilledema which, after a thorough workup, including magnetic resonance imaging and lumbar puncture, was confirmed to be benign Drusen's papilledema. She was free of tumour at one-year follow-up with imaging and endoscopy.

\section{DISCUSSION}

IMTs were established as single entities in 1994 by the WHO classification. In the 2013 classification, IMTs are recognized as a clonal neoplasm that are considered to have intermediate malignancy that

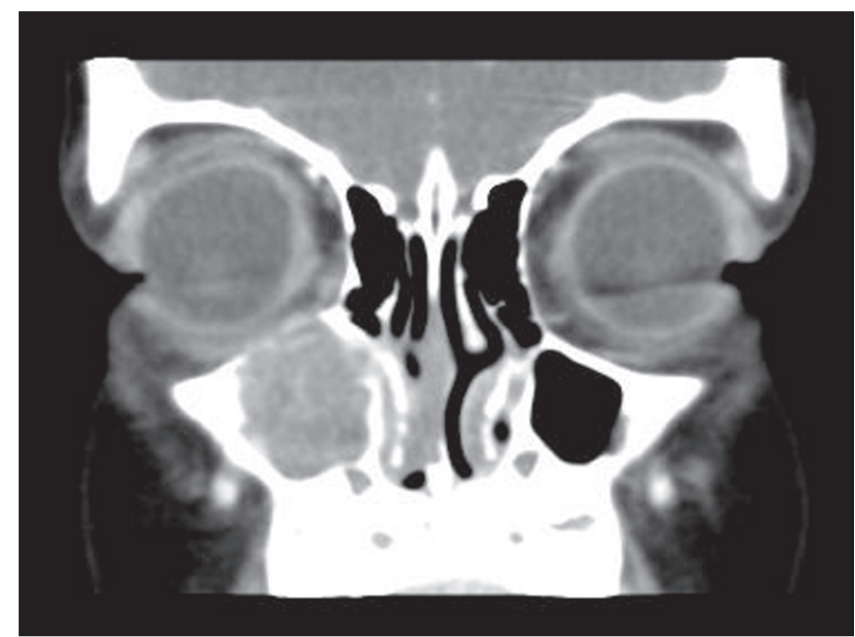

Figure 1) Computed tomography imaging confirming a mass in the maxillary sinus extending into the lacrimal sac

rarely metastasizes (1). IMTs have previously been described by various diagnoses such as inflammatory pseudotumour, xanthogranuloma, histiocytoma, plasma cell granuloma, inflammatory fibromyxoid tumour and myofibroblastic proliferation. IMTs are most commonly observed in the first two decades of life, primarily in the lungs. Extrapulmonary tumours are rarely reported, but are mostly restricted to the omentum and mesentery (3). IMTs usually present as a solid mass, although systemic symptoms, such as fevers, malaise and weight loss, are also observed in $15 \%$ to $20 \%$ of cases (4). On computed tomography imaging, IMTs appear as a mildly enhancing soft tissue mass with no calcification. Fewer than $5 \%$ of cases have metastases (5).

ALK expression is restricted to the brain, testes and small intestine, but is not expressed in normal lymphoid tissue. Originally, it was cloned as a fusion partner in anaplastic large cell lymphoma (hence,

${ }^{1}$ Division of Plastic Surgery; ${ }^{2}$ Division of Otolaryngology; ${ }^{3}$ Division of Pathology and Laboratory Medicine, Akron Children's Hospital, Akron, Ohio, USA

Correspondence: Dr AS Murthy, Akron Children's Hospital, One Perkins Square, Akron, Ohio 44308, USA.

Telephone 330-543-4970, e-mail amurthy@chmca.org 


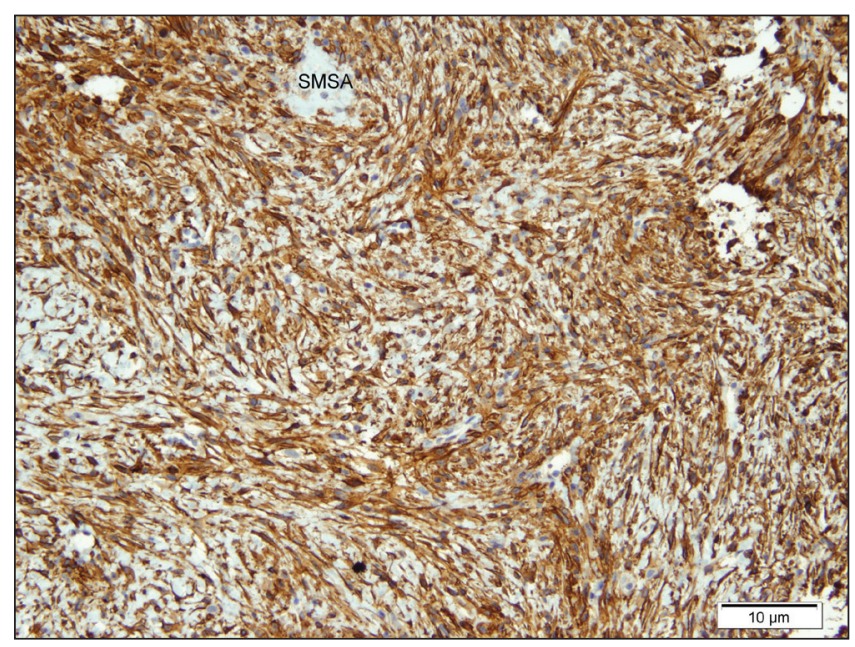

Figure 2) Immunohistochemical study showing uniform expression of smooth muscle actin (SMSA) in a characteristic 'tram track' pattern supportive of myofibroblastic differentiation. Original magnification $\times 10$

the name 'anaplastic lymphoma kinase'). It was later discovered that this gene was implicated in the pathogenesis of IMT. In fact, approximately $30 \%$ of IMTs in the pediatric population contain clonal cytogenetic rearrangements that activate the ALK receptor tyrosine kinase gene on chromosome 2p23 (6). The etiology of IMTs is unknown. The

\section{REFERENCES}

1. Fletcher CD, Mertens F, Bridge JA, Hogendorn, eds. In: WHO Classification of Tumours of Soft Tissue and Bone. International Agency for Research on Cancer, 4th edn. Geneva: WHO Press, 2013.

2. Lee H-M, Choi G, Choi CS, Kim CH, Lee SH. Inflammatory pseudotumor of the maxillary sinus. Otolaryngol Head Neck Surg 2001;125:565-6.

3. Gleason BC, Hornick JL. Inflammatory myofibroblastic tumours: Where are we now? J Clin Pathol 2008;61:428.

4. Coffin CM, Hornick JL, Fletcher CD. Inflammatory myofibroblastic tumor: Comparison of clinicopathologic, histologic and immunohistochemical features including ALK expression in atypical and aggressive cases. Am J Surg Pathol 2007;31:509-20.

5. Dimitrakopoulos I, Psomaderis K, Karakasis D. Inflammatory mysofibroblastic tumor of the maxillary sinus: A case report. J Oral Maxillofac Surg 2007;65:323-6.

6. Alaggio R,Cecchetto G, Bisogno G, et al. Inflammatory myofibroblastic tumors in childhood: A report from the Italian Cooperative Group studies. Cancer 2010;116:216-26. role of viruses, such as human herpesvirus 8 and Epstein-Barr virus, has been investigated; however, the evidence is inconclusive (6-8). It is believed that in ALK-positive tumours, the ALK gene on chromosome 2 is fused to one of several partners, such as nonmuscular tropomyosin 3, which can confer proliferative properties to the tumour $(9,10)$. Although controversial, atypia and positive ALK status are more frequent in aggressive tumours; however, negative ALK status is observed in recurring or metastatic tumours $(4,6,8,9)$.

IMTs represent a spectrum of chronic inflammation secondary to an intermediate neoplastic process. This explains why anti-inflammatory treatment with corticosteroids is not successful in treating these tumours. However, with locally aggressive or large tumours and, especially if ALK expression is negative, surgical resection with clear margins is the preferred treatment and necessary to prevent recurrence (7-9). A recent meta-analysis found that treatment of IMTs of the maxillary sinus with corticosteroids was not successful in $66 \%$ of cases reported in the literature. In a similar review, all cases that underwent surgical resection with clear margins had tumour-free survival $(3,9)$. Recurrence was observed with cases of incomplete resection in spite of postoperative radiation or corticosteroid therapy $(6,10)$.

Novel therapies, such as ALK inhibitors, are currently being investigated in the preclinical and clinical trial setting. ALK-directed therapy may emerge as a highly effective treatment option for a subset of patients with IMT (11). However, based on current standard of care, it is our recommendation to treat IMTs with surgical resection along with clear margins.

7. Mehta B, Mascarenhas L, Zhou S, Wang L, Venkatramani R. Inflammatory myofibroblastic tumors in childhood. Pediatr Hematol Oncol August 29, 2013 (Epub ahead of print).

8. Mergan F, Jaubert F, Sauvat F, et al. Inflammatorymyofibroblastic tumor in children: Clinical review with anaplastic lymphoma kinase, Epstein-Barr virus, and human herpesvirus 8 detection analysis. J Pediatr Surg 2005;40:1581-6.

9. Lu ZJ, Zhou SH, Yan SX, Yao HT. Anaplastic lymphoma kinase expression and prognosis in inflammatory myofibroblastic tumours of the maxillary sinus. J Int Med Res 2009;37:2000-8.

10. Newlin HE, Werning JW, Mendenhall WM. Plasma cell granuloma of the maxillary sinus: A case report and literature review. Head Neck 2005;27:722-8.

11. Tothova Z, Wagner AJ. Anaplastic lymphoma kinase-directed therapy in inflammatory myofibroblastic tumors. Curr Opin Oncol 2012;24:409-13. 